\title{
The Construction of Aircraft Design Courses Facing the Cultivation of Innovative Talents
}

\author{
Hai An \\ College of Aerospace and Civil Engineering, Harbin Engineering University, Harbin 150001, Heilongiiang, China \\ Email: anhai@hrbeu.edu.cn
}

\begin{abstract}
As people pay more and more attention to innovative talents, cultivating students' innovative ability has become the main starting point and ultimate goal of talent training in major universities. China needs a large number of innovative talents to realize the great national rejuvenation and to build the motherland's important reserve talent pool. Therefore, the effective cultivation of innovative ability is of great significance to the realization of the national talent training strategic goal. Aircraft-related majors are an important part of the national aerospace and aerospace majors, and training a group of innovative aerospace professionals is an important measure that the party and the country cannot ignore. This article takes how to train a group of innovative talents as a research starting point, and discusses the construction of aircraft-related professional courses and teaching strategies for the cultivation of innovative talents.
\end{abstract}

Keywords: cultivation of innovative talents, aircraft design major, course construction

\section{Introduction}

The subject of aircraft design is a technical course that integrates basic theories of comprehensive design and design process. To truly realize the development of scientific research and technological breakthroughs, theoretical innovation and scientific research talent innovation, we must start with the teaching reform of specialized courses, deepen it to practice, and do a good job in the construction of aircraft design courses. Generally speaking, the design process needs to go through multiple links such as theoretical verification, actual manufacturing, and experimental analysis. However, the actual situation facing today is that traditional teaching methods have some shortcomings and are not suitable for the current innovative talent training plan. Therefore, it is necessary to explore feasible discipline implementation plans for the above-mentioned topics.

\section{Disadvantages of traditional aircraft design professional teaching methods}

There are many shortcomings in the traditional teaching methods of aircraft design, which are caused by many historical and practical reasons. On the one hand, compared with foreign countries, China's aircraft design graduate students have a late start in practice and teaching, with a weak foundation, and a long-term lack of professional supporting facilities. The needs for professional skills and experimental training are difficult to meet. On the other hand, in the traditional technical training model, theoretical and technical teaching in the classroom accounted for the vast majority, resulting in most students can only move from one book to the next, and there is a serious lack of opportunities to combine theory and practice. . There are also internships in traditional training programs, but generally, graduate students are organized to visit the aircraft design and manufacturer sites. Although it can help students enhance their intuition and understanding of the subject, due to the cumbersome graduation design and production tasks of the school itself, it cannot provide students with enough time for more in-depth practical exploration. In essence, practical activities can also be said to be "arbitrary." For some students who participate in the scientific research of the tutor, usually only one aspect of aircraft design is involved. To fully understand the characteristics of various disciplines of aircraft design, it is difficult to cultivate students' ability to think about problems from the perspective of aircraft life cycle. Since each student's participation in the scientific research tasks undertaken by the supervisor can usually be broken down or distinguished, it is not necessary to require multiple people to work together.

The design and manufacture of modern aviation vehicles is a huge and complex systematic project, which requires hundreds of celebrities or even thousands of crews to complete. Team spirit is also the focus of training that must be paid attention to in the professional training of aircraft design. Without teamwork, it is impossible to deal with the relationship between multiple disciplines. Unfortunately, most talent training methods based on scientific research projects do not have such knowledge. For some students with strong professional interest and eager to conduct in-depth research on a certain aspect of the subject, due to the lack of financial support and professional teacher guidance, part of their potential is eventually buried by a unified education method. Based on the above problems, the traditional teaching methods have the following 
basic problems:

\subsection{Insufficient instillation of innovative consciousness}

From the perspective of traditional teaching, most schools only assume the responsibility of educating students on theories of learning. Due to the constraints of the school's objective conditions and the lack of strong awareness of the school leaders at that time, when formulating teaching work plans, they often neglected to cultivate innovative talents and the inculcation of innovative awareness. Most college teachers also pay attention to theoretical research, and they don't pay enough attention to this aspect. Application practice opportunities are missing.

\subsection{Focus on theory and light on practice}

At present, the work of colleges and universities in this field is mainly concentrated on theoretical teaching, and students have fewer opportunities to accept practice. Even if there is a chance, only a few people can do it. The large-scale and implementation of courses and practices, the cost of the school is high, the funding is insufficient, and the effect is not good. As a result, students lack opportunities to actively participate in internships, and practice concepts are also suppressed, which greatly impacts teachers' motivation for innovation. Therefore, it is necessary to find a way and method that can completely break this situation, and use this as a breakthrough point to formulate practical and feasible strategies for cultivating talents in colleges and universities.

\subsection{Insufficient construction of the innovation environment}

At present, most of the internal environment of colleges and universities is still dominated by academic research, and there are few efforts in school-enterprise cooperation, talent transfer and training. Therefore, the efficiency of talent training is very low. At present, various national undertakings urgently need advanced and innovative talents. Therefore, as the most important talent training and transportation base, colleges and universities must re-form a talent training plan according to the current situation to ensure the normal operation and stable development of various undertakings in the country. Therefore, it is necessary to increase the intensity of the innovation environment to meet its actual needs.

\section{Practice}

\subsection{In-class reforms}

\subsubsection{Streamline the curriculum}

Streamline the curriculum. At present, many courses in this major are not able to adapt to current trends. The speed of technological progress in our country is very fast, and there is an urgent need for more technical and managerial talents. As a comprehensive discipline with strong professionalism, strong engineering technology, and more professional and domain knowledge, the aircraft design major must further strengthen the identification of major and field-related courses, formulate curriculum design plans with practical value, and coordinate majors The setting is professional and reasonable. Formulate implementation measures and plans related to practice and evaluation, such as appropriately expanding the proportion of credits related to the experimental and educational practice courses of this project, in order to divert students' attention and cultivate students' sense of innovation. In addition, pay attention to the control of the course and give students as much space as possible. Teachers should formulate a reasonable teaching plan to stimulate students' interest in participation.

\subsubsection{Combine practice}

Setting up specific practical courses not only requires relevant professionals to effectively promote and improve teaching in actual teaching and management at the technical level, but also requires acquisition of relatively coordinated teaching resources at the technical level. These are guaranteed practical courses. Important basis for the smooth development of the country. The school should formulate an effective resource cost list according to the current actual situation and needs, and create a teaching condition suitable for practical courses. Secondly, in teaching, teachers need to choose appropriate teaching techniques and methods, such as grouping, collaboration, and independent completion. Thus, while stimulating students' interest in practice, as much as possible to ensure the smooth development of teaching. The traditional teaching methods of speaking are mostly based on the form of speaking used by teachers in the classroom, while students are immersed in theory. Now, teachers should also actively change their teaching methods and concepts, and point out the problems of each student in a timely manner. Establish a reasonable evaluation and evaluation plan, and continuously encourage college students to realize the improvement of their innovative ability while finding their own shortcomings.

\subsection{Extracurricular training}

For some personnel and students with high interest in aviation work and good practical skills, the school should organize 
these students to participate in the school's aviation model team and actively participate in various aviation model competitions with scientific research. Many experts in the field of aerospace technology have pointed out that the design and production of aviation models play an important role in aircraft design. The self-designed aviation experimental flight simulator can train students in three extremely important majors in comprehensive aircraft design: flight dynamics, aircraft components, and power equipment. People who have engaged in model aircraft activities in China may not have made achievements in the aviation industry. On the contrary, many people who have outstanding achievements in the aviation industry have engaged in model aircraft activities in their youth. A designer engaged in aircraft model design said: "Designing and manufacturing aircraft models is a small system project." Building an airplane model group is a very good platform for students who have spare capacity and strongly hope to make a difference in the aviation field to further study and exercise. The whole process from the beginning of preparation to participating in the competition can not only improve the students' flying equipment and design skills, but also cultivate and enhance the students' team consciousness, so that students can practice and practice in all aspects of professional knowledge, skills, and personality. exercise.

Every student has his own advantages. Some people may be very good at calculating parameters and theoretical design; some may also be particularly good at manufacturing and helping to coordinate and solve machine problems; others may be good at innovation, innovative thinking, etc. Therefore, everyone is good at different research directions. This requires meticulous assessment of the current specific conditions of students in various professional colleges, and then conduct targeted training. Design majors are different from other types of majors. Although theoretical knowledge is important, creative thinking cannot be missing. Therefore, in many cases, students need to be analyzed from multiple angles to avoid errors in direction. At the same time, students can be encouraged to set up interest clubs after class and equip them with professional teachers, such as an aviation module, which is designed for reserve talents who specialize in aircraft design.

\subsection{Practical support}

Aerospace engineering graduate experimental class, aviation model team activities, and graduate innovation fund, these three links constitute the three key components of aerospace engineering innovation practice education and learning method reform, which has realized the transformation from serious study to pioneering and independent innovation. The three-stage leap, which is in line with the trend of reforming the traditional teaching method based on knowledge instillation to the teaching method of exploring innovative talents. Through this kind of teaching reform, China has established and perfected a set of experimental teaching curriculum system for aviation professional and technical personnel at all levels, which combines both inside and outside classes, covering students inside and outside the school, and even international students. This omni-directional, multi-level aircraft design professional and technical personnel training system has greatly improved the teaching effect of aircraft design. In the process of classroom teaching reform, the dominant position of students in the classroom has been consolidated and strengthened. Classroom teaching reform has broadened and improved students' mastery and practice of basic knowledge to a large extent. At the same time, benefiting from the changes in classroom teaching, students have also become active participants in classroom reforms. Under the help and guidance of teachers, they will continue to give full play to the effects of classroom teaching reforms, and continue to enrich and accumulate their own achievements in the form of seniors and younger students. The learning results ensure the continuous improvement and improvement of the quality of practical classroom teaching, so as to continuously stimulate students' autonomy, initiative and creativity in the classroom teaching process.

Practical design is the most important stage from theory to social reality. In actual work, good and practical design ideas must be further checked and verified through practice to ensure that their design is effective. Because of its wide range of majors and involving more types of knowledge, design is often difficult, and the cost of design is not borne by ordinary students alone. To further implement the innovative talent training strategy, the school must start with the creation and construction of a complete practical support environment. Created from the designated fund application process, evaluation plan and other matters, this is a supplement to the complete curriculum system. Therefore, it is necessary to pay attention to it.

\section{Conclusion}

To sum up, there are obvious problems and shortcomings in the teaching of aircraft design in colleges and universities, which restrict the development of China's aerospace industry. This article combines the current teaching practice of the aircraft design course, and discusses the effective measures of the course reform from the perspective of improving the teaching effect and promoting the cultivation of innovative talents. In actual teaching, it is necessary to analyze the actual situation of current teaching, overcome difficulties and drawbacks, and strive to train high-quality people to contribute to the construction of the national professional talent team. 


\section{References}

[1] Huang Min, Hao Jingru, Yang Qingdong, et al. Mechanical engineering practice teaching reform for application-oriented and innovative talent training [J]. China Electric Power Education, 2012.

[2] Mei Huaping, Xu Gang. Mechanical engineering professional practice teaching reform for application-oriented and innovative talent training [J]. Heilongjiang Science and Technology Information, 2016.

[3] Hu Huiqiang. Analysis of Talent Needs in Zhejiang General Aviation Industry and Research on Training Countermeasures [J]. Science and Technology Innovation and Application, 2017, (6).

[4] Dong Nianqing. The development status, difficulties and countermeasures of China's general aviation [J]. Journal of Beijing Institute of Technology (Social Sciences), 2014, (1).

[5] Liu Lijun. The construction of a diversified general aviation talent training model[J]. Journal of Shenyang University of Aeronautics and Astronautics, 2017, (2). 